\title{
A Statistical and Analytical Study of the Factors that Impede Women's Participation in the Economic Activities in Kirkuk, Iraq
}

\author{
HASAN Sabah Haseeb ${ }^{1}$, AL-HARTHI Abdulrahim Khalaf Rahi ${ }^{2}$, \\ KAREEM Anwar Dhia'a Abdul ${ }^{3}$
}

${ }^{1,3}$ College of Administration and Economics, Kirkuk University, Kirkuk, (IRAQ)

${ }^{2}$ College of Administration and Economics, Mustansiriyah University, Baghdad, (IRAQ)

\begin{abstract}
This study deals with the issue of women's participation in economic activities in Kirkuk, Iraq, and the main factors that impede this participation. It employs the questionnaire designed for this purpose and distributed to women in Kirkuk. Additionally, the principal components method is used to reduce the number of the variables involved in the analysis to the lowest number of factors that serve as the best representation of the variables. The findings demonstrate that eight main factors representing the study variables. These factors explained about $70 \%$ of their total variance. Based on these factors, conclusions and recommendations are made on the study subject.
\end{abstract}

Keywords: Iraqi Woman, Factor analysis, principal component method

JEL: L26

UDK: 005.32:331.1-055.2(567)

005.94

\section{Introduction}

The woman is an essential part of society in its public and private fields, and its present and future. She is a key means for reproducing the fundamental values and principles of society, whether through her role as a mother or participation in society. Hence, women have assumed a pivotal position enabling them to play a prominent role whose effects are reflected in their various contributions at the various cultural, social, political and economic levels.

However, this role has sometimes been exposed to challenges that often arise from the nature of the circumstantial, social and ethnic environments surrounding the status and role of women in those societies. This has often weakened the role played by women in some fields and even marginalized it [1].

Hence, the importance of this study lies in highlighting the most important factors that impede women's participation in various economic activities in Iraqi society, especially in Kirkuk. It is important to mention that Kirkuk is one of the most important cities in Iraq economically. The main goal of this study is applying factor analysis using the method of principal components analysis to the variables identified as may affect women's participation in economic activity in Kirkuk. It also aims to explain the extent to which many of these variables can be represented by principal components fewer than variables included in the analysis. Thus, the results obtained from this method are utilized to reduce the number of variables. Consequently, the components resulting from the analysis are key indicators representing the original variables better representation and explain the majority of their variability [2]. 


\section{Literature Review}

It is important to mention that Kirkuk is one of the most important cities in Iraq economically. In this section, we highlight the recent researches that studied Iraqi women affairs. The researches have pointed on the obstacles that prevent their participation in different life sides and roles in the Iraqi economy.

The study in [3] showed that the Iraqi women had a good right in different country sectors.

However, situations associated with wars and economic embargo on Iraq and internal conflicts have influenced to their roles. Furthermore, the study summarized the challenges and available chances in the Iraqi economy. Moreover, the authors listed recommendation about how to enhance women roles in the Iraqi economy.

In 2016, the central statistical organization of the Iraqi ministry of planning [4] conducted a study to create a statistical database about the situation of Iraqi women in rural place. The aim of the survey was to prepare the required recommendations that may promote rural women in different sectors. Briefly, main objectives were increasing the efforts to educate the women of their role and impact in: 1) Agricultural development process; 2) Economic and social rights; 3) Legacy; 4) Incubation; 5) Education; 6) Health; and 7) Gender equality.

The authors in [5] studied women situation after 2003 when their participation has increased due to establishing political parties and pluralism system. Additionally, the study has presented several negative situations because of deteriorating in security events in some places and the associations that opposed to woman freedom and impeded their roles.

\section{Theoretical Section}

This study is based on the most important methods of factor analysis. It is the method of principal components that will be relied upon in determining the factors that represent the variables of the phenomenon studied better representation. Accordingly, it explains the greater proportion of their total variation, as mentioned earlier.

\section{Factor Analysis [6]}

Factor analysis seeks to detect a relatively small number of non-observed (latent) variables that adequately represent the relative relationships between a large number of measured variables. Therefore, each latent variable represents a common variation between several measured variables. This procedure facilitates dealing with several variables through the use of fewer latent variables that represent the study variables regardless of their diversity. These are called "Latent Factors".

Generally, Factor analysis starts with the correlation's matrix, which includes correlation coefficients among row variables that are also repeated in columns. As the variables found in the matrix are the same as those found in columns. The diagonal cells divide the matrix into two triangles of cells; each has the value of (1) because they indicate the association of each variable with itself. Then, the correlation matrix is analyzed using factor analysis to obtain as few factors as possible, enabling to express the greatest variation among these variables.

\section{Objectives of Factor Analysis}

Factor analysis performs various functions that can be expressed by the following two main objectives [7]:

Reducing the number of measured variables to a fewer number of latent variables. 
Detecting the latent factor structure or indicative areas that underlie the multiplicity of measured variables.

\section{Procedures of Factor Analysis [8]}

1. Analysis of the matrix of correlations between the measured variables.

2. Applying a method of extracting or deriving factors.

3. Rotation methods to obtain significant factors or to facilitate the interpretation of factors.

4. Calculating factor scores for each individual (i.e., a score for each individual for each of the extracted factors).

The assumptions required by factor analysis are the nature of distributing the scores of measured variables and level of their measurement (i.e., the sample). Then, it requires testing the validity of the data or correlations matrix to apply factor analysis to it. After confirming that the data are suitable for factor analysis, the next step is implementing factor analysis methods in processing the data to extract the factors. Next, using simulations for determining the number of extracted factors. After that, the interpretation of extracted factors by referring to Rotation Methods, including Orthogonal Rotation and Oblique Rotation. Kaiser-Mayer-Olkin (KMO) is one of the metrics used to measure the degree of correlations between variables at the matrix level. KMO aims to estimate the adequacy or efficiency of investigation. Additionally, it is an indicator for calculating the volume of correlation coefficients of the measured variables to partial correlation coefficients. KMO equation can be expressed as follows [9]:

$$
\text { KMO }=\frac{\sum_{\text {(correlation) }} 2}{\sum_{\text {(correlation) }} 2+\sum_{\text {(partial correlation) }} 2}
$$

Both the numerator and denominator are close or equal when the total squares of the partial correlation coefficients are small compared to those of the correlation coefficients. Consequently, KMO is close to or equal 1. Furthermore, KMO ranges between zero and 1, where, zero indicates that factor analysis is inappropriate. However, when it is close to 1, the correlations matrix is valid for factor analysis. Finally, it is worth mentioning that Kaiser states that this measure is accepted when it is not less than 0.5.

\section{Evaluating the Validity of Correlations Matrix for Factor Analysis}

1. Most correlations coefficients should exceed 0.30 and be significant, and the statistical significance is unreliable.

2. The absolute value of correlation matrix determinant must be greater than (0.00001). Consequently, it signifies the lack of very high correlations and the absence of linear dependence among variables [10], [11].

3. Bartlett's Test should be statistically significant and indicate that the correlations matrix is not the identity matrix (free of relationships) [12]. However, it is available to a minimum of relations. In this case, it must be strengthened by other tests.

4. Based on Kaiser's simulation, KMO test for all matrix should be higher than 0.50 . This signifies that the level of correlation between each variable to other variables in the correlation's matrix is sufficient to conduct a factor analysis. 


\section{Factor Analysis Methods}

After testing the validity of the correlation matrix to factor analysis, one of factor analysis methods is apply to detect the latent factor structure that summarizes the various interrelationships among the measured variables [7].

There are two methods of factor analysis:1) Principal Component; and 2) a set of methods that all based on Common Variance. To identify the difference between them, it is necessary to clarify some concepts represented by Common Variance, Unique Variance, Specific Variance and Error Variance. The maximum variance of the variable is 1 . This general variance that composes the variables is divided into two types:

1. Common Variance: represents the common area between variables or the ratio of variance shared by a set of items or measured variables.

2. Unique Variance: it is the variance in which the variable does not engage with other variables. In other words, it corresponds to the variance after deleting common variance from the total variance of the measured variable that equals 1 . It is divided into two types:

a. Specific Variance: it is variance of the variable and forms its identity and distinguishes it from other variables.

b. Error Variance: it is independent of specific variance and its display of irregularity. Its size is estimated by using Reliability, particularly Alpha for internal consistency.

\section{Principal Component Method [13]}

This method is based on all variance that composes the measured variables, whether it is a common or unique variance of its two types of specific and error variance. Method of the principal component in analyzing the correlations matrix between variables is applied to detect groups whose components are highly correlated. So, these variables represent a linear combination to achieve the possible maximum total of the correlation's squares between this combination and the original variables. This combination is known as factor, which represents the maximum variance in measurement items. The correlation coefficients between this combination and the original items are called Loadings. After extracting the first factor, the second factor is extracted by configuring a second-best linear combination of variables with other weights so that the second factor is independent of the first one. Accordingly, the method of principal components analysis extracts gradual factors in terms of their importance, starting with the first factor and ending with the last one. Hence, the first factor is characterized by representing the largest proportion of variance and containing the most eigenvalue. This case indicates that its relation to the variables it represents is stronger than the relation of other factors extracted from the variables they represent.

On the other hand, the analysis method based on general variance is consistent with the method of principal components in that the extracted factors are independent and not related to each other. However, it differs from the method of principal components, where it derives factors from employing common variance excluding unique variance. The problem that faced the methods of extracting factors (based on common variance) is the mechanism for determining common variance or value of commonalities that the process of extracting factors is based on it. This mechanism is the basis for the difference between the types of factor analysis based on common variance.

The value of communalities, which are equal to the total squares of a particular item loadings on the components or factors extracted. Furthermore, it represents the ratio of variance explained by the factors extracted in a certain item or a certain measurement variable, It is found 
to be equal to (1) when using the principal components method because it uses all the variance that is determined by (1) at the level of the measured variable. Whereas, the value of communalities of items or variables measured when using principal components method are mostly less than (1). The reason is that this method only uses the variance part which consists of a variable that is common with variance of other measured variables and excludes specific and error variance. Value of communalities may be equal to $0.60,0.80$ or 0.70 or any other value, which is necessarily less than (1) where (1) represents all variance which consists of measured variable).

\section{Applied Section}

\section{Women's Economic Position in Kirkuk}

Kirkuk is a city located at Iraq's northern region about $255 \mathrm{Km}$ from Baghdad. It is the fifth among Iraq's cities in terms of population, which is one million and 400 thousand inhabitants according to the census of 2014. The city is a crucial city with economic importance. Furthermore, among the factors that played a role in its importance is oil and fertility of its agricultural lands. Moreover, to its distinctive geographical and commercial location, which makes it a link between Central and Northern Iraq [14].

To identify the extent of women's participation in economic activity in Kirkuk, some information on commercial and industrial centers and the construction sector were collected for the period (2015-2018). The data collected showed women's position and involvement in economic activity in Kirkuk. The information was collected from Kirkuk Chamber of Commerce and Industry. The information was on the numbers of the following points:

1. Participants in training courses.

2. Loan recipients to create small projects.

3. Number and type of projects for females.

4. Employees in State's institutions.

Based on Table 1, the number of females was less than males who participated in training courses for economic projects in Kirkuk. Hence, females represented about 29\%; while males represented by $71 \%$.

Table 1. Number of males, females, and percentage of participants in training courses

\begin{tabular}{|c|c|c|}
\hline Gender & Number & Percentage (\%) \\
\hline Males & 885 & 0.71 \\
\hline Females & 358 & 0.29 \\
\hline Total & 1243 & \\
\hline
\end{tabular}

Table 2 shows the number of loan recipients to create small projects. The number of females was 41 much lower than that of males (which was 1521) in obtaining the loan for economic projects in Kirkuk city. Therefore, females represented 3\%; whereas males represented by $97 \%$.

Table 2. Number of males, females, and percentage of loan recipients to create small projects

\begin{tabular}{|c|c|c|}
\hline Gender & Number & Percentage (\%) \\
\hline Males & 1521 & 0.97 \\
\hline Females & 41 & 0.03 \\
\hline Total & 1562 & \\
\hline
\end{tabular}


Table 3 refers to the types of economic projects created by women in Kirkuk. It is noted that the sewing project was of more interest for women than other projects reaching $51 \%$, (i.e., more than half of other economic projects). There were different projects forming about $37 \%$, and $12 \%$ for the project of women's barbershop.

Table 3. Number and percentage of projects created by females

\begin{tabular}{|c|c|c|}
\hline Project type & Number & Percentage (\%) \\
\hline Women's barbershop & 5 & 0.12 \\
\hline Sewing & 21 & 0.51 \\
\hline Different projects & 15 & 0.37 \\
\hline Total & 41 & \\
\hline
\end{tabular}

Finally, Table 4 refers to the number of employees in the State's institutions. It is clear that the number of female employees is (39), which is also lower than that of males (129). It seems that the State gives more employment opportunities for males than females. Hence, the percentage of male employees is represented by $77 \%$ versus $23 \%$ for females.

Table 4. Number of males, females and percentage of employees in State's institutions

\begin{tabular}{|c|c|c|}
\hline Gender & Number & Percentage (\%) \\
\hline Males & 129 & 0.77 \\
\hline Females & 39 & 0.23 \\
\hline Total & 168 & \\
\hline
\end{tabular}

\section{Data Description}

To obtain data on the reality of women in Kirkuk, the questionnaire designed for this purpose was adopted in this study. It consisted of 26 questions, believing that they affected the determination of the fundamental obstacles to women's participation in economic activity in this Iraqi city. Each question was represented by the symbol Xi, $(\mathrm{i}=1,2, \ldots, 26)$. These questions are defined as follows:

$\mathrm{X} 1$ : The dominant male culture in society is a major obstacle for women in the economic field.

$\mathrm{X} 2$ : Considering domestic work as a basic work for women and work in the economic field and investment is for men.

$\mathrm{X} 3$ : The inferior view of women to be as a worker and subordinate, not as a businesswoman and head of work.

$\mathrm{X} 4$ : Identifying the type of women's self-employment and confining them to specific occupations, such as opening beauty salons, establishing nurseries, etc.

X5: The prevailing social violence against women reduces creativity, skill, and leadership for women.

X6: Women's fear of exploiting their social reputation during labor competition in the economic field.

X7: Prevailing social customs and traditions are generally a fundamental barrier.

X8: The weakness of the private sector itself reduces jobs opportunities and women's participation in them.

X9: The weakness and backwardness of technology and traditional work have led to limited participation of women.

X10: Weak and lack of sponsorship (funding) for productive projects by the government.

$\mathrm{X} 11$ : The lack of insurance companies to protect productive projects and capital in the case of disasters and unexpected situations.

X12: The lack of law for establishing small projects, which are considered the most important economic, productive field where women are involved. 
X13: The lack of a product protection law, which in turn leads to the poor marketing process.

X14: The lack of a consumer protection law that has a direct impact on competition and progress.

X15: The lack of courts for addressing problems and disputes between work and capital, which makes it difficult for women to enter this field.

X16: Weak public sector cooperation with the private sector leads to weakness and underdevelopment of the private sector.

X17: The lack of a clear policy on the part of the government to regulate, develop, and encourage the private sector has led women to move away from the field of economic work.

X18: Poor social awareness about women's participation and employment in the private sector has led women to tend toward the public sector and government occupations.

X19: The small number of organizations and associations working in the economic field has a significant impact on the poor awareness and leadership of women to work in the private sector.

X20: The negative role of media in showing women as a tool for commercial advertisements only, not as successful businesswomen in society.

$\mathrm{X} 21$ : Limited participation and lack of experience and practice for women in the economic field have led to men's monopolism of business associations with all their branches.

X22: The lack of social balance (man-woman) in administrative bodies of associations and unions of business with all branches, leading to weakness of moral support for women.

$\mathrm{X} 23$ : There is no law or instructions to encourage women to participate in economic work.

X24: Civil Status Code stipulates the distribution of inheritance as 1:2 between man and woman.

X25: There are instructions issued that a woman should not obtain a passport without the consent of her guardian until a specific age.

$\mathrm{X} 26$ : Income tax for husband and wife is calculated as one and not as two separate persons.

After distributing the questionnaire to a sample consisting of (84) women from Kirkuk who work in various economic activities, they filled in its items and then gave it to the researchers. The answers are shown in the appendix (1). The appendix clarifies the total number of women's answers to the questions (distributed by the four items).

\section{Results and Discussion}

SPSS (18.0) was used to obtain all results for descriptive statistics and the principal component method based on the data that collected from the questionnaire [15], [11].

Table 5 shows an overview of the variables (questions) under study. The arithmetic means, the standard deviations and the number of values were included in the analysis for each variable. From the initial analysis of the relationships among (26) variables involved in factor analysis using the principal components method, the correlation matrix was different from the unit matrix. Furthermore, its determinant was greater than $(0.00001)$, where the specified value was equal to (0.0000493). This outcome means that there is no strong correlations and lack of linear dependence among variables. 
Table 5. Descriptive statistics of the variables

\begin{tabular}{|c|c|c|c|c|c|c|c|}
\hline Variable & Mean & Std. Deviation & $\mathrm{N}$ & Variable & Mean & Std. Deviation & $\mathrm{N}$ \\
\hline $\mathrm{X} 1$ & 2.7024 & 1.09522 & 84 & $\mathrm{X} 16$ & 3.0357 & .78305 & 84 \\
\hline $\mathrm{X} 2$ & 2.3095 & 1.21215 & 84 & $\mathrm{X} 17$ & 2.9881 & .82862 & 84 \\
\hline X3 & 2.1429 & 1.17343 & 84 & $\mathrm{X} 18$ & 3.1667 & .78898 & 84 \\
\hline $\mathrm{X} 4$ & 2.2024 & 1.14891 & 84 & X19 & 3.0238 & .82105 & 84 \\
\hline $\mathrm{X} 5$ & 3.0476 & .82000 & 84 & $\mathrm{X} 20$ & 3.1310 & .90220 & 84 \\
\hline X6 & 2.8095 & 1.05826 & 84 & $\mathrm{X} 21$ & 2.9286 & .88883 & 84 \\
\hline $\mathrm{X} 7$ & 2.8452 & .97553 & 84 & $\mathrm{X} 22$ & 2.8333 & .92922 & 84 \\
\hline $\mathrm{X} 8$ & 3.1190 & .79766 & 84 & $\mathrm{X} 23$ & 2.7857 & .93230 & 84 \\
\hline X9 & 2.5000 & 1.00000 & 84 & $\mathrm{X} 24$ & 2.7857 & 1.13440 & 84 \\
\hline $\mathrm{X} 10$ & 3.1667 & .92922 & 84 & $\mathrm{X} 25$ & 2.5833 & 1.08892 & 84 \\
\hline $\mathrm{X} 11$ & 3.1429 & .80873 & 84 & $\mathrm{X} 26$ & 2.3810 & 1.12908 & 84 \\
\hline $\mathrm{X} 12$ & 2.8810 & .76685 & 84 & & & & \\
\hline $\mathrm{X} 13$ & 2.8690 & .86121 & 84 & & & & \\
\hline $\mathrm{X} 14$ & 3.0000 & .80660 & 84 & & & & \\
\hline $\mathrm{X} 15$ & 2.8333 & .94210 & 84 & & & & \\
\hline
\end{tabular}

Regarding KMO and Bartlett's test, Table 6 clarifies that the KMO value is equal to (0.669), which is greater than (0.5). This result indicates that the level of correlation of each variable to other variables (in the correlation matrix) is sufficient for conducting factor analysis as well as the adequacy of sample size. The result of Bartlett's test also indicates that it is statistically significant (0.000), which is less than (0.05). This is shown by the test result in Table 3 , which confirms the correlation matrix not as the unit matrix (i.e., free of relationships), but there is a minimum of relationships among variables. Hence, factor analysis was conducted using the method of principal components.

Table 6. KMO and Bartlett's Test

Kaiser-Meyer-Olkin Measure of Sampling Adequacy. Bartlett's Test of Sphericity

\begin{tabular}{|l|c|}
\hline Approx. Chi-Square & 898.160 \\
\hline Df & 325 \\
\hline Sig. & .000 \\
\hline
\end{tabular}

Based on Table 7 below, the values of communalities of variables illustrate the ratio of variable variance that can be explained by the factors extracted. The variance ratios ranged between $77 \%$ and $57 \%$. For example, the value (0.707) of variable X1 explains that the extracted factors explain about $71 \%$ of the variable X1. Accordingly, the interpreted variance has been obtained.

Table 7. Communalities

\begin{tabular}{|c|c|c|c|c|c|}
\hline Variable & Initial & Extraction & Variable & Initial & Extraction \\
\hline $\mathrm{X} 1$ & 1.000 & .707 & $\mathrm{X} 14$ & 1.000 & .773 \\
\hline $\mathrm{X} 2$ & 1.000 & .755 & $\mathrm{X} 15$ & 1.000 & .713 \\
\hline $\mathrm{X} 3$ & 1.000 & .775 & $\mathrm{X} 16$ & 1.000 & .577 \\
\hline $\mathrm{X} 4$ & 1.000 & .743 & $\mathrm{X} 17$ & 1.000 & .655 \\
\hline $\mathrm{X} 5$ & 1.000 & .737 & $\mathrm{X} 18$ & 1.000 & .655 \\
\hline $\mathrm{X} 6$ & 1.000 & .749 & $\mathrm{X} 19$ & 1.000 & .639 \\
\hline $\mathrm{X} 7$ & 1.000 & .767 & $\mathrm{X} 20$ & 1.000 & .742 \\
\hline $\mathrm{X} 8$ & 1.000 & .689 & $\mathrm{X} 21$ & 1.000 & .685 \\
\hline $\mathrm{X} 9$ & 1.000 & .619 & $\mathrm{X} 22$ & 1.000 & .570 \\
\hline $\mathrm{X} 10$ & 1.000 & .643 & $\mathrm{X} 23$ & 1.000 & .666 \\
\hline $\mathrm{X} 11$ & 1.000 & .693 & $\mathrm{X} 24$ & 1.000 & .715 \\
\hline $\mathrm{X} 12$ & 1.000 & .717 & $\mathrm{X} 25$ & 1.000 & .730 \\
\hline $\mathrm{X} 13$ & 1.000 & .678 & $\mathrm{X} 26$ & 1.000 & .661 \\
\hline
\end{tabular}


Table 8. Total variance explained

\begin{tabular}{|c|c|c|c|c|}
\hline \multirow{2}{*}{ Component } & \multicolumn{3}{|c|}{ Initial Eigenvalues } & \multirow{2}{*}{$\begin{array}{c}\text { Extraction Sums of Squared } \\
\text { Loadings }\end{array}$} \\
\hline & Total & $\begin{array}{c}\text { Percentage of Variance } \\
(\%)\end{array}$ & $\begin{array}{c}\text { Cumulative Percentage } \\
(\%)\end{array}$ & \\
\hline 1 & 5.813 & 22.357 & 22.357 & 5.813 \\
\hline 2 & 2.991 & 11.504 & 33.860 & 2.991 \\
\hline 3 & 2.187 & 8.413 & 42.273 & 2.187 \\
\hline 4 & 1.706 & 6.585 & 48.842 & 1.708 \\
\hline 5 & 1.639 & 6.303 & 55.145 & 1.639 \\
\hline 6 & 1.352 & 5.201 & 60.346 & 1.352 \\
\hline 7 & 1.289 & 4.956 & 65.302 & 1.289 \\
\hline 8 & 1.072 & 4.124 & 69.426 & 1.072 \\
\hline 9 & .879 & 3.381 & 72.807 & \\
\hline 10 & .776 & 2.986 & 75.793 & \\
\hline 11 & .748 & 2.876 & 78.669 & \\
\hline 12 & .705 & 2.712 & 81.381 & \\
\hline 13 & .679 & 2.611 & 83.992 & \\
\hline 14 & .587 & 2.258 & 86.250 & \\
\hline 15 & .481 & 1.850 & 88.101 & \\
\hline 16 & .437 & 1.681 & 89.781 & \\
\hline 17 & .428 & 1.647 & 91.429 & \\
\hline 18 & .399 & 1.536 & 92.965 & \\
\hline 19 & .331 & 1.275 & 94.240 & \\
\hline 20 & .318 & 1.221 & 95.461 & \\
\hline 21 & .259 & 0.998 & 96.459 & \\
\hline 22 & .246 & .948 & 97.407 & \\
\hline 23 & .221 & .848 & 98.255 & \\
\hline 24 & .190 & .731 & 98.987 & \\
\hline 25 & .150 & .576 & 99.563 & \\
\hline 26 & .114 & .437 & 100.000 & \\
\hline
\end{tabular}

Table 8 demonstrates that there are eight basic factors that control the phenomenon under study because its eigenvalues are greater than one. This means that the method of principal compounds reduced the relationship among variables to eight factors representing a certain percentage of the variable's information. The proportions of variance explained by each factor are as follows:

1. The first factor: $22.357 \%$.

2. The second factor: $11.504 \%$.

3. The third factor: $8.413 \%$.

4. The fourth factor: $6.585 \%$.

5. The fifth factor: $6.303 \%$.

6. The sixth factor: $5.201 \%$.

7. The seventh factor: $4.956 \%$.

8. The eighth factor: $4.124 \%$.

As shown in Table 9, the proportion of total variance explained by these eight factors is estimated at $69.426 \%$. 
Table 9. Total variance explained

\begin{tabular}{|c|c|c|}
\hline \multirow{2}{*}{ Component } & \multicolumn{2}{|c|}{ Extraction Sums of Squared Loadings } \\
\cline { 2 - 3 } & Percentage of Variance (\%) & Cumulative Percentage (\%) \\
\hline 1 & 22.357 & 22.357 \\
\hline 2 & 11.504 & 33.860 \\
\hline 3 & 8.413 & 42.273 \\
\hline 4 & 6.568 & 48.842 \\
\hline 5 & 6.303 & 55.145 \\
\hline 6 & 5.201 & 60.346 \\
\hline 7 & 4.956 & 65.302 \\
\hline 8 & 4.124 & 69.426 \\
\hline
\end{tabular}

Table 10 is a matrix of factors that represents the loadings of factors which reflect the degree to which each variable is related to a particular factor. The variable that is related to it helps to describe it well when the loading of a particular factor is greater than (0.3). On this basis, the results are as follows:

- The first factor includes these variables: X1, X2, X3, X5, X6, X7, X8, X9, X10, X11, X12, X13, X14, X15, X16, X17, X18, X19, X20, X21, X22, X23 and X26.

- The second factor includes these variables: X1, X2, X3, X4, X6, X8, X15, X17, $\mathrm{X} 18, \mathrm{X} 21, \mathrm{X} 22$ and X23.

- The third factor includes these variables: X1, X8, X10, X11, X13, X14, X18, X22 and $\mathrm{X} 26$.

- The fourth factor includes these variables: X4, X5, X24 and X25.

- The fifth factor includes these variables: X1, X4, X6, X15, X20 and X25.

- The sixth factor includes these variables: X4, X5, X13, X21 and X26.

- The seventh factor includes these variables: X5, X11, X14 and X19.

- The eighth factor includes these variables: X3, X7 and X8.

Then, the component transformation matrix was utilized to determine whether the rotation process is necessary. If the transformation matrix is unit, it means that the rotation process is not necessary for the study. Based on results found in Table 11, the transformation matrix is not unit, so the rotation process is necessary for this work.

Table 10. Component Matrix

\begin{tabular}{|c|c|c|c|c|c|c|c|c|}
\hline \multirow{2}{*}{ Variable } & \multicolumn{9}{|c|}{ Component } \\
\cline { 2 - 9 } & 1 & 2 & 3 & 4 & 5 & 6 & 7 & 8 \\
\hline $\mathrm{X} 1$ & .388 & .480 & .383 & .024 & -.328 & .115 & -.104 & .217 \\
\hline $\mathrm{X} 2$ & .302 & .704 & .074 & -.177 & .311 & -.029 & -.057 & .176 \\
\hline $\mathrm{X} 3$ & .365 & .569 & .230 & -.138 & .190 & .076 & .259 & .370 \\
\hline $\mathrm{X} 4$ & .177 & .593 & .129 & -.307 & .366 & -.296 & -.094 & -.135 \\
\hline $\mathrm{X} 5$ & .449 & .253 & -.179 & .455 & .029 & -.334 & .322 & -.126 \\
\hline $\mathrm{X} 6$ & .392 & .560 & .199 & .013 & -.388 & .207 & .090 & -.203 \\
\hline $\mathrm{X} 7$ & .523 & .229 & .205 & -.089 & -.183 & -.271 & -.073 & -.528 \\
\hline $\mathrm{X} 8$ & .349 & .310 & -.477 & .130 & -.162 & -.110 & .216 & .376 \\
\hline $\mathrm{X} 9$ & .615 & .160 & -.135 & .070 & -.243 & -.264 & -.246 & -.050 \\
\hline $\mathrm{X} 10$ & .479 & -.020 & -.547 & .045 & -.218 & .163 & .148 & -.122 \\
\hline $\mathrm{X} 11$ & .452 & .045 & -.576 & -.127 & .079 & .145 & .309 & -.124 \\
\hline $\mathrm{X} 12$ & .728 & -.007 & -.166 & -.232 & -.004 & -.200 & -.208 & -.033 \\
\hline $\mathrm{X} 13$ & .400 & .038 & -.427 & .052 & .125 & .554 & -.088 & .061 \\
\hline $\mathrm{X} 14$ & .381 & .131 & -.398 & -.061 & -.044 & .204 & -.633 & .143 \\
\hline $\mathrm{X} 15$ & .491 & -.332 & -.122 & -.155 & .487 & -.039 & .252 & -.167 \\
\hline $\mathrm{X} 16$ & .680 & -.187 & .079 & -.132 & .091 & .122 & .071 & -.082 \\
\hline $\mathrm{X} 17$ & .651 & -.401 & .124 & -.193 & -.061 & -.029 & -.085 & .007 \\
\hline $\mathrm{X} 18$ & .560 & -.377 & .367 & -.122 & -.150 & .136 & -.092 & -.257 \\
\hline
\end{tabular}




\begin{tabular}{|c|c|c|c|c|c|c|c|c|}
\hline $\mathrm{X} 19$ & .436 & -.205 & -.185 & .288 & .258 & -.205 & -.340 & .226 \\
\hline $\mathrm{X} 20$ & .467 & -.177 & .060 & .199 & -.561 & -.178 & .228 & .247 \\
\hline $\mathrm{X} 21$ & .504 & -.369 & .209 & .239 & .112 & -.312 & -.155 & .014 \\
\hline $\mathrm{X} 22$ & .457 & -.402 & .308 & -.069 & -.105 & .159 & .252 & .122 \\
\hline $\mathrm{X} 23$ & .608 & -.370 & .130 & -.167 & .274 & -.071 & .142 & .183 \\
\hline $\mathrm{X} 24$ & .235 & -.010 & .218 & .677 & .092 & .274 & -.194 & -.133 \\
\hline $\mathrm{X} 25$ & .148 & .218 & .154 & .695 & .357 & .019 & .088 & -.051 \\
\hline $\mathrm{X} 26$ & .499 & .115 & .413 & .032 & .191 & .432 & .033 & .054 \\
\hline
\end{tabular}

Orthogonal Rotation method (Varma) was employed to improve the position of the extracted factors by maximizing large loadings and reducing small loadings. As listed in Table 12, after the rotation process, the matrix of rotated factors was obtained. Based on the outputs of factor analysis after rotation, the following is concluded:

- The contribution of variables (X12, X15, X16, X17, X18, X20, X21, X22, X23 and $\mathrm{X} 26)$ to the formation of the first factor.

- The contribution of variables $(\mathrm{X} 1, \mathrm{X} 2, \mathrm{X} 3, \mathrm{X} 4$ and $\mathrm{X} 26)$ to the formation of the second factor.

- The contribution of variables (X8, X10, X11, X13, X14 and X15) to the formation of the third factor.

- The contribution of variables (X1, X6, X15, X19, X20 and X26) to the formation of the fourth factor.

- The contribution of variables (X5, X24, X25 and X26) to the formation of the fifth factor.

- The contribution of variables (X5, X8, X9, X20 and X21) to the formation of the sixth factor.

- The contribution of variables (X4, X5, X6, X7, X9 and X12) to the formation of the seventh factor.

- The contribution of variables (X9, X12, X13, X14 and X19) to the formation of the eighth factor.

Table 11. Component Transformation Matrix

\begin{tabular}{|c|c|c|c|c|c|c|c|c|}
\hline Component & 1 & 2 & 3 & 4 & 5 & 6 & 7 & 8 \\
\hline 1 & .685 & .251 & .367 & .152 & .170 & .290 & .334 & .292 \\
\hline 2 & -.542 & .690 & .089 & .404 & .105 & .056 & .214 & -.005 \\
\hline 3 & .395 & .166 & -.711 & .359 & .207 & -.216 & .030 & -.304 \\
\hline 4 & -.202 & -.281 & -.064 & .013 & .853 & .364 & -.115 & .060 \\
\hline 5 & .099 & .502 & .026 & -.676 & .336 & -.373 & -.168 & .021 \\
\hline 6 & .099 & -.088 & .461 & .468 & .180 & -.525 & -.492 & .000 \\
\hline 7 & .112 & .100 & .311 & -.077 & -.010 & .324 & -.127 & -.868 \\
\hline 8 & .093 & .292 & -.195 & .053 & -.211 & .463 & -.736 & .253 \\
\hline
\end{tabular}

Table 12. Rotated Component Matrix

\begin{tabular}{|c|c|c|c|c|c|c|c|c|}
\hline \multirow{2}{*}{ variable } & \multicolumn{9}{|c|}{ Component } \\
\cline { 2 - 10 } & 1 & 2 & 3 & 4 & 5 & 6 & 7 & 8 \\
\hline $\mathrm{X} 1$ & .149 & .377 & -.116 & .685 & .040 & .176 & .099 & .131 \\
\hline $\mathrm{X} 2$ & -.071 & .827 & .075 & .144 & .052 & .009 & .114 & .152 \\
\hline $\mathrm{X} 3$ & .150 & .784 & .078 & .273 & .048 & .182 & -.108 & -.102 \\
\hline $\mathrm{X} 4$ & -.103 & .722 & -.084 & -.077 & -.044 & -.129 & .421 & .046 \\
\hline $\mathrm{X} 5$ & .002 & .169 & .257 & -.096 & .427 & .559 & .358 & -.100 \\
\hline $\mathrm{X} 6$ & .014 & .251 & .205 & .699 & .126 & .077 & .357 & -.086 \\
\hline $\mathrm{X} 7$ & .231 & .119 & .023 & .218 & .082 & .031 & .802 & .009 \\
\hline $\mathrm{X} 8$ & -.111 & .246 & .425 & .070 & -.052 & .631 & -.069 & .157 \\
\hline $\mathrm{X} 9$ & .185 & .085 & .137 & .168 & .038 & .369 & .466 & .420 \\
\hline $\mathrm{X} 10$ & .114 & -.142 & .700 & .074 & -.015 & .259 & .161 & .145 \\
\hline
\end{tabular}

${ }^{\circ}$ Filodiritto Editore 


\begin{tabular}{|l|c|c|c|c|c|c|c|c|}
\hline $\mathrm{X} 11$ & .128 & .106 & .777 & -.138 & -.070 & .148 & .125 & .002 \\
\hline $\mathrm{X} 12$ & .427 & .172 & .271 & -.043 & -.110 & .130 & .496 & .393 \\
\hline $\mathrm{X} 13$ & .134 & .056 & .675 & .107 & .164 & -.122 & -.184 & .337 \\
\hline $\mathrm{X} 14$ & -.004 & .052 & .322 & .144 & -.040 & -.086 & .092 & .793 \\
\hline $\mathrm{X} 15$ & .559 & .148 & .348 & -.480 & .076 & -.052 & .118 & -.071 \\
\hline $\mathrm{X} 16$ & .638 & .085 & .299 & .036 & .087 & -.031 & .244 & .066 \\
\hline $\mathrm{X} 17$ & .740 & -.051 & .070 & .017 & -.111 & .118 & .132 & .237 \\
\hline $\mathrm{X} 18$ & .745 & -.123 & -.050 & .235 & .004 & -.030 & .107 & .122 \\
\hline $\mathrm{X} 19$ & .270 & .044 & .011 & -.309 & .260 & .280 & -.026 & .567 \\
\hline $\mathrm{X} 20$ & .373 & -.228 & .030 & .314 & -.028 & .666 & .084 & -.021 \\
\hline $\mathrm{X} 21$ & .565 & -.020 & -.249 & -.191 & .225 & .353 & .041 & .299 \\
\hline $\mathrm{X} 22$ & .701 & -.129 & .064 & .143 & .029 & .062 & -.019 & -.179 \\
\hline $\mathrm{X} 23$ & .749 & .160 & .103 & -.235 & .001 & .105 & .029 & .043 \\
\hline $\mathrm{X} 24$ & .113 & -.153 & -.009 & .190 & .782 & -.059 & .015 & .167 \\
\hline $\mathrm{X} 25$ & -.062 & .166 & -.009 & -.071 & .823 & .098 & .039 & -.067 \\
\hline $\mathrm{X} 26$ & .507 & .340 & .102 & .344 & .341 & -.190 & -.086 & .010 \\
\hline
\end{tabular}

\section{Conclusions}

Factor analysis was employed using the method of principal components. It was based on correlation coefficients between variables. The analysis results indicated that there are eight main factors affecting women's participation in the economic field as a businesswoman.

Variables with a loading value of (0.3) and above and with Eigenvalue of more than one was considered. These eight factors were able to explain about $70 \%$ of the total variance. The study reached the following results:

1. The study showed through descriptive statistics that the situation of women is at its lowest levels in terms of their participation in economic activity as a businesswoman and the decline of their activity in education, nursing and opening of barbershops.

2. The lack of women's involvement in the economic field to take their natural role in contributing to management and business has marginalized them, allowing their breadwinner to practice domestic violence to them.

3. Traditional customs and traditions, male culture, and the inferior view of women are a major obstacle to women's participation in the economic field and as a businesswoman.

4. The lack of insurance companies to protect small projects that can be led by women or co-managed by them and frighten them from disasters, fires and wars is a crucial factor in the decline of their role and participation.

5. The weakness of the private sector, the lack of public sector support, security, and economic conditions and instability have led to women's weak participation and leadership of economic projects.

6. Tests used in data analysis showed that the matrix of correlations among variables could be analyzed using factor analysis as well as they are free of linear dependence and high correlations.

7. The first factor was the most important, explaining about $(22.35 \%)$ of the total variance and included (23) variables in the social and economic field and the nature of work that women can perform. Hence, most researchers consider these variables to have a significant impact on the decline of the role of women and the lack of their involvement in the economic field.

8. The second factor explained about (11.504\%) of the total variance and included (12) variables and so on the rest of the factors. However, the common characteristic of all these factors confirms that the social factor, customs, traditions, male culture, and the inferior view of women are common factors. These factors significantly affect women's non-involvement in economic activity as a businesswoman and leader of economic projects. 


\section{Recommendations}

In light of the findings, the study recommends the following:

1. An intensive awareness campaign by civil society organizations on the importance of women's role and their right to participate as a businesswoman and leader of some economic projects.

2. Demonstrate women's ability to manage projects and to advertise successful projects led by women or that have contributed to their success and the propagation of these experiences and projects by media.

3. Support of the private sector, the establishment of a fund to support small projects, providing the necessary materials for the success of these projects and assigning their responsibility to women for their leadership and demonstrating their capabilities.

4. Enact legislation and laws encouraging women and protecting women's rights from waste and loss.

5. Opening workshops and courses to develop women's capacities in senior and middle management and project management will raise the reality of women and encourage them to engage in economic activity and manage projects.

\section{REFERENCES}

1. Iraqi Ministry of Planning, (2016), The reality of rural women in Iraq, Central Statistical Organization, Human Development Statistics, available online (https://mop.gov.iq/en/).

2. Musa, Firas Jassim, (2018), The Reality of Iraqi Women: Overwhelming Challenges and Absent Solutions, Working Paper, Research Department, Iraqi Parliament, Republic of Iraq.

3. Spencer, N. H. (2012). Essentials of multivariate data analysis. Chapman and hall/CRC.

4. Shatha Salem Dali, \& Abdul Karim Jabbar Shingar, (2015). Empowering women in Iraq and their role in promoting the Iraqi economy, Al-Qadisiyah Journal of Administrative and Economic Sciences, 17 (2), pp. 100-112.

5. Omar Bale, Ahmed Hama. Gharib, (2018), The reality of Iraqi women and their future challenges, Journal of Social Sciences, Arab Democratic Center for Strategic, Political and Economic Studies, Berlin, Germany, No. 03, pp. 70-82.

6. Rencher, A. C., (2002), Methods of Multivariate Analysis, 2nd Ed., Wiley Interscience, A John Wiley \& Sons, Inc.

7. Afifi, A., May, S., \& Clark, V. A. (2012). Practical multivariate analysis. CRC Press.

8. Al-Rawi, Ziad Rashad, (2017), multivariable statistical analysis methods, Arab Institute for Training and Statistical Research.

9. Cerny, B. A., \& Kaiser, H. F. (1977). A study of a measure of sampling adequacy for factor-analytic correlation matrices. Multivariate behavioral research, 12(1), pp. 43-47.

10. Haitovsky, Y. (1969). Multicollinearity in regression analysis: Comment. The Review of economics and statistics, pp. 486-489.

11. Field, A. (2009). Discovering Statistics Using SPSS. $3^{\text {rd }}$ Edition, SAGE Publications Ltd. London.

12. Sncdccor, G. W., \& Cochran, W. G. (1980). Statistical methods, $6^{\text {th }}$ ed., Iowa State University Press. Ames, lowa, USA.

13. Morrison, Donald F., (1978), Multivariate Statistical Methods, $2^{\text {nd }}$ Ed., McGraw. Hill. Inc.

14. Kirkuk, Investment Authority, (2011), Investor Guide in Kirkuk, USAID, Trade Program for Economic Development in the Provinces, Iraq.

15. Jawdah, Mahfoudh, (2009), Advanced Statistical Analysis using SPSS, Wael Publishing and Distribution House, Jordan.

\section{Article history:}

- $\quad$ Received 25 May 2019

- Accepted 28 Juny 2019 